\title{
Plasma $n-3$ fatty acids and psychological distress in aboriginal Cree Indians (Canada)
}

\author{
Michel Lucas ${ }^{1}$, Éric Dewailly ${ }^{1,2, *}+$, Carole Blanchet ${ }^{1}$, Suzanne Gingras ${ }^{1}$ and \\ Bruce J Holub ${ }^{3}$ \\ 'Public Health Research Unit, Laval University Medical Research Centre (CHUQ), Sainte-Foy, Québec, Canada: \\ ${ }^{2}$ Department of Social and Preventive Medicine, Laval University, Sainte-Foy, Québec, Canada: ${ }^{3}$ Department of \\ Human Biology and Nutritional Sciences, University of Guelph, Guelph, Ontario, Canada
}

Submitted 19 June 2008: Accepted 11 December 2008: First published online 26 February 2009

\begin{abstract}
Objective: To examine the relationship between psychological distress (PD) and plasma $n$-3 long-chain (LC) PUFA, i.e. EPA, docosapentaenoic acid (DPA $n$-3) and DHA.

Design: Population-based, cross-sectional Santé-Québec Health Survey (1991). Participants were categorized as high-level PD if they scored over the 80th percentile of the PD Index in the Santé-Québec Survey; non-distressed subjects were those who scored less than this cut-off. Associations between tertiles of $n$ - 3 fatty acids (FA) and the risk of high-level PD were expressed as odds ratios, with the lowest tertile as the reference group.

Setting: Québec, Canada.

Subjects: Data were analysed from a representative sample of 852 James Bay Cree Indian adults aged 18 years and over.

Results: Proportions of $n$ - 3 FA were statistically significantly lower in the PD than in the non-distressed group. After adjustment for confounders, EPA was the only individual $n-3$ FA significantly associated with the risk of high-level PD. Combinations of $\mathrm{EPA}+\mathrm{DHA}$ or $\mathrm{EPA}+\mathrm{DPA} n-3+\mathrm{DHA}$ or the sum of $n$ - 3 were also associated with the risk of high-level PD. Compared with the lowest tertile of $\mathrm{EPA}+\mathrm{DHA}$, the OR for high-level PD was 0.89 (95\% CI 0.59, 1.36) for the second and $0.56(95 \% \mathrm{CI} 0 \cdot 32,0 \cdot 98)$ for the third tertile, after controlling for confounders. Conclusions: In the present retrospective, cross-sectional study, we found that proportions of $n$-3 LC PUFA in plasma phospholipids, markers of $n$ - 3 LC PUFA consumption from fish, were inversely associated with PD.
\end{abstract}

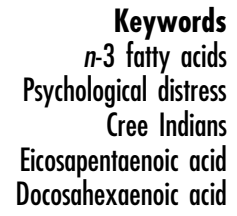

Keywords n-3 fatty acids Cree Indians Docosahexaenoic acid
The shift away from traditional lifestyles and diets is associated with increasing health problems in several native populations ${ }^{(1,2)}$. Some aboriginal groups have reported evidence of severe psychological distress (PD), with high rates of depression, suicide, violence, alcoholism and substance abuse, the most profound impact being felt by the young ${ }^{(1,3-7)}$. However, the psychiatric literature on the Cree is scarce. In a study of mental health service use between 1986 and 1988, depression was the most common psychiatric illness noted among 242 Cree receiving help from nursing and medical personnel ${ }^{(8)}$. Their traditional eating habits have been changed by cultural and environmental factors linked to modernization $^{(9-11)}$. In these communities, we noted that plasma proportions of EPA + DHA were two times higher among

$\uparrow$ Correspondence address: Delta Building \#2 - Office 600, 2875 Laurier Blvd, 6th Floor, Sainte-Foy (QC), Canada, G1V $2 \mathrm{M} 2$. older than among younger adults, which suggests that the former consume more traditional foods, such as fish ${ }^{(12)}$.

It has been postulated that dietary changes occurring in our societies, mainly a decrease in $n-3$ (omega-3) longchain (LC) PUFA and an increase in $n-6$ (omega-6) consumption, could be contributing to the growing incidence of depression ${ }^{(13)}$. Epidemiological and clinical studies indicate that $n$-3 LC PUFA are associated with benefits in mood disorders, particularly depression ${ }^{(14,15)}$. Although man is technically capable of endogenously synthesizing EPA and DHA from the $n-3$ precursor $\alpha$-linolenic acid $(\alpha$-LNA) in plants, this conversion is a very inefficient way of increasing DHA in tissues ${ }^{(16)}$. Therefore, in general, EPA and DHA measurements in blood reflect habitual dietary $n$-3 LC PUFA intake from fish ${ }^{(17-19)}$.

Several biological mechanisms might potentially explain the impact on and research interest in $n$ - 3 fatty acids (FA) in psychiatry. Phospholipids (PL), which contain 
FA, are major components of neuronal cell membranes and are essential for normal brain functions ${ }^{(20)}$. PUFA comprise one-third of all FA in the brain ${ }^{(21,22)}$. PUFA in the brain are mainly represented by two FA, DHA and the $n-6$ arachidonic acid (AA), which constitute $\approx 80 \%$ of total PUFA ${ }^{(21,22)}$. Animal experiments have indicated that $n$ - 3 deficiency alters serotonin neurotransmission ${ }^{(23-27)}$. In man, higher plasma DHA has been demonstrated to predict concentrations of serotonin and dopamine metabolites in cerebrospinal fluid $^{(28,29)}$. Both EPA and DHA, which compete with AA for inclusion in neuronal membranes, have anti-inflammatory effects $^{(30,31)} \cdot n$-3 LC PUFA may also exert other influences on brain biochemistry, such as membrane structure and fluidity; enzyme, receptor, ion channel, second messenger and blood-brain barrier functions; and increase cerebral blood flow ${ }^{(20,32,33)}$.

Different risk and protective factors of mental health have been identified among the James Bay Cree ${ }^{(34)}$. However, the role of their traditional diet has received scant attention with regard to mental health. A generalized measure of PD was adopted in a cross-sectional survey undertaken by the Government of Quebec among the James Bay Cree in $1991^{(10)}$. We considered it important to examine the potential role of $n$ - 3 LC PUFA in PD in James Bay Cree Indians.

\section{Methods}

\section{Study design and population}

The Santé-Québec Health Survey among the James Bay Cree in 1991 has been described in detail elsewhere ${ }^{(10,12)}$. Briefly, Santé-Québec, an agency of the Quebec Health and Social Services Ministry, undertook a health survey of the Cree population in 1991. The apparent long delay between the availability of these data and the results presented here is mainly due to a lack of staff and time. The primary objective of the survey was to collect relevant information on the physical, social and psychosocial health of the Cree population $^{(10)}$. These data were gathered in several stages with home interviews and clinic visits. The survey targeted all private Cree households located in the nine communities of the James Bay region. Of the household respondents, 943 participants submitted to clinical measurements and blood tests. Of these, fifty did not have information on PD, twentysix did not have FA measurements and fifteen were pregnant women; all of them were therefore excluded from the present analysis. The final sample size analysed was 852 . In the survey, signed informed consent was obtained from the study subjects before inclusion. The study protocol was approved by the Clinical Research Deontology Committee of Laval University.

\section{Psychological distress}

PD among the Cree was measured via a modified version of the fourteen-Item PD Index used in the 1987
Table 1 The Psychological Distress Index Santé-Québec Survey (PDISQS-14) used in the Santé-Québec Health Survey among the James Bay Cree Indians

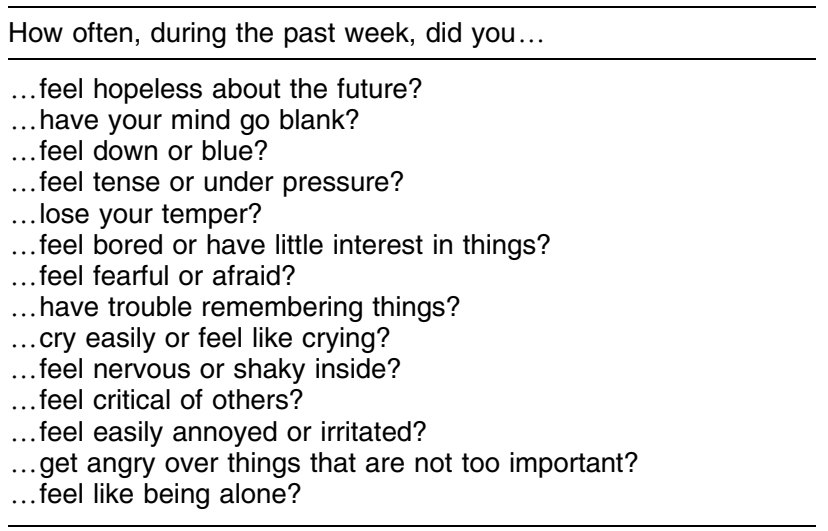

Each item had four possible answers coded as: $0=$ never, $1=$ once in a while, 2 = fairly often and 3 = very often.

Santé-Québec Survey (PDISQS-14) ${ }^{(35,36)}$. The PDISQS-14 is an adaptation of the Psychiatric Symptom Index (PSI), developed and validated by Ilfeld ${ }^{(37,38)}$. The self-administered PDISQS-14 contains fourteen statements addressing psychological symptoms experienced in the previous week (Table 1). The structure of the PSI is based on four distinct dimensions (depression, anxiety, aggressiveness and psychomotor perturbations) connected at a second level with the more general concept of $\mathrm{PD}^{(39)}$. Scores range from a minimum of 0 to a maximum of 100 . Internal consistency of the scale within Cree respondents was found to be satisfactory (Cronbach's $\alpha=0 \cdot 94)^{(34)}$. As in the 1987 SantéQuébec master survey ${ }^{(40)}$, a high level of PD was defined by any score above the 80th percentile of the index distribution observed in the Cree. Participants were categorized as having high-level PD if they scored over the 80th percentile of the PDISQS-14 (score of 30.95). Non-distressed participants were those scoring less than this cut-off. One hundred and fifty-four participants, sixty-three men and ninety-one women, scored above the cut-off.

\section{Plasma phospholipid fatty acids}

Blood samples were collected in the fasting state. Plasma samples, stored at $-80^{\circ} \mathrm{C}$ for $\leq 4$ months, were measured for the FA composition of PL. FA analysis of these plasma biomarkers (PL) was based on previously published methods ${ }^{(41)}$. The results and procedures have been described in detail elsewhere ${ }^{(12)}$. Briefly, the FA composition of plasma PL was determined by capillary GLC. FA proportions in plasma PL were expressed as percentages of the total area of all FA peaks from $14: 0$ to $24: 1$. In the present study, the plasma PL proportions of FA corresponded to the relative percentages of total FA by weight. Only the proportions of PUFA are reported for the present purpose.

\section{Statistical analysis}

The statistical distribution of plasma FA was checked and found to be skewed for some FA. Therefore, we undertook 
log transformation to compare FA between PD groups. Arithmetic means were also calculated for the FA data to facilitate comparisons with other studies. Student's $t$ test was performed to compare FA between PD groups. ANOVA with Bonferroni correction for multiple comparisons $(P<0 \cdot 0025)$ was conducted for EPA + DHA plasma PL according to quintiles of PDISQS-14 scores. The distribution of $n$-3 FA was considered to compute cut-off points for tertiles of $n$-3. Associations between tertiles of $n$-3 FA and the risk of high-level PD were expressed as odds ratios, with the lowest tertile as the reference group. Trends across tertiles of $n-3$ FA were discerned by assigning the log-transformed median value for each tertile to all subjects in that group. Selection of covariables was based on simulation studies ${ }^{(42-44)}$, which suggested a minimum number of events per variable (minimally 10-15 events were needed per covariate). Co-variables were selected without the predictor of interest in the multivariate model and were based on backward selection, considering a liberal $P$ value criterion of 0.5 for all relevant covariates ${ }^{(42)}$. The covariates tested were: age, gender, smoking status, total plasma cholesterol $(<5 \cdot 2 \mathrm{mmol} / \mathrm{l})$, physical activities in leisure time, $\geq 1$ chronic medical illness in lifetime, BMI $\left(\mathrm{kg} / \mathrm{m}^{2}\right)$, education, occupation, marital status and no recent stress events. For the variable 'recent stress events', subjects were asked if they had experienced any of six stressful events during the past 12 months: moved away from the family, lost their job, were rejected or disapproved of by the community, suffered a serious illness, lost a family member (death of husband/wife/common-law spouse) or lost a relative (death of father/mother/family member when they were under the age of 12 years). A favourable answer (yes) was coded as 1 for each of these events (on scores between 0 and 7). The variable 'recent stress events' was dichotomized, meaning that the subject either experienced stress or not $($ score $=0)$. The final models satisfied collinearity criteria. Statistical analyses were performed with the SAS for Windows statistical software package version 9 (SAS Institute, Inc., Cary, NC, USA). Differences between groups and associations were considered significant at $P<0 \cdot 05$ (bilateral).

\section{Results}

Table 2 reports study subject characteristics according to high-level PD. The prevalence of high-level PD in this population was $17 \cdot 9 \%$. Mean age of the participants was $35 \cdot 2$ (SD 13.9) years. A higher proportion of younger, single and more educated subjects were in the high-level PD category. Figure 1 shows EPA + DHA plasma PL

Table 2 Characteristics of the study subjects (\%) according to high-level psychological distress (PD): James Bay Cree Indian adults aged 18 years and over $(n 852)$

\begin{tabular}{|c|c|c|c|}
\hline & \multicolumn{2}{|c|}{ High-level PD* } & \multirow[b]{2}{*}{$P$ value } \\
\hline & Yes $(n 154)$ & No $(n 698)$ & \\
\hline Age (years) & & & $<0.0001$ \\
\hline $18-24$ & $42 \cdot 9$ & $23 \cdot 5$ & \\
\hline $25-44$ & $50 \cdot 7$ & $43 \cdot 8$ & \\
\hline$\geq 45$ & $6 \cdot 5$ & $32 \cdot 7$ & \\
\hline Female & $60 \cdot 6$ & $52 \cdot 1$ & 0.0538 \\
\hline Total plasma cholesterol $<5 \cdot 2(\mathrm{mmol} / \mathrm{l})$ & $81 \cdot 5$ & $65 \cdot 7$ & 0.0002 \\
\hline Single & $44 \cdot 4$ & $29 \cdot 3$ & 0.0003 \\
\hline More than elementary school education & $84 \cdot 4$ & $57 \cdot 3$ & $<0.0001$ \\
\hline Unemployedt & $18 \cdot 0$ & $13 \cdot 2$ & $0 \cdot 1213$ \\
\hline$\geq 1$ chronic medical illness in lifetime & $42 \cdot 0$ & $55 \cdot 0$ & 0.0032 \\
\hline Recent stress events & $54 \cdot 3$ & $44 \cdot 6$ & 0.0305 \\
\hline Smoking status & & & 0.0006 \\
\hline Never smoked & 3.5 & 8.9 & \\
\hline Ex-smokers & $32 \cdot 4$ & $43 \cdot 0$ & \\
\hline Smokersł & $64 \cdot 2$ & $48 \cdot 1$ & \\
\hline Used drugs in lifetime§ & $64 \cdot 6$ & $35 \cdot 0$ & $<0.0001$ \\
\hline CAGE score $\geq 2 \|$ & $58 \cdot 0$ & $37 \cdot 4$ & $<0 \cdot 0001$ \\
\hline BMI $\left(\mathrm{kg} / \mathrm{m}^{2}\right)$ & & & 0.7634 \\
\hline$<25$ & $15 \cdot 6$ & $17 \cdot 8$ & \\
\hline $25-30$ & $35 \cdot 3$ & $33 \cdot 2$ & \\
\hline$\geq 30$ & $49 \cdot 2$ & $48 \cdot \overline{9}$ & \\
\hline
\end{tabular}

*Participants were included as high-level PD if they scored over the 80th percentile of the PD Index Santé-Québec Survey (PDISQS14). Non-distressed participants were those scoring less than this cut-off.

tThe unemployed group combined those receiving unemployment insurance or welfare, looking for a job and unemployed. The remunerated employment group combined professionals, executives, white- and blue-collar workers, trappers, houseworkers and independent workers.

¥Combined regular and occasional smokers.

§Combined users and ex-users of marijuana, hashish, cocaine, substance sniffing (solvents, glue, gasoline) and other illicit drugs. To be considered 'abstinent', subjects must never have consumed any illicit drugs.

IICAGE (Cutting down, Annoyance by criticism, Guilty feelings, and Eye-openers) alcoholism risk questionnaire.

-BMl is weight $(\mathrm{kg})$ divided by the square of height $\left(\mathrm{m}^{2}\right)$. Only three subjects (two in the non-distressed group) had BMl $<18 \cdot 5 \mathrm{~kg} / \mathrm{m}^{2}$. 


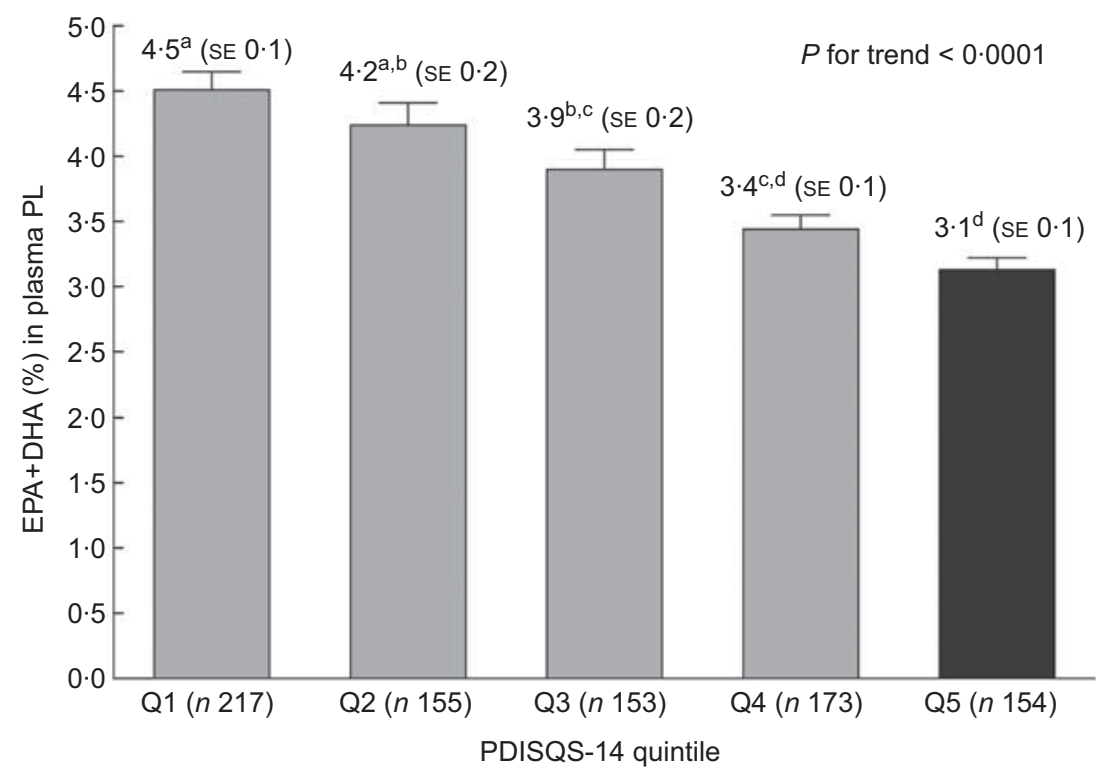

Fig. 1 Mean proportion of EPA + DHA in plasma phospholipids (PL) according to quintile of Psychological Distress Index SantéQuébec Survey (PDISQS-14) scores among James Bay Cree Indians. Higher quintiles signify higher PD scores ( $\boldsymbol{\square}$, high-level PD group; $\square$, non-distressed groups). Values are means with their standard errors shown by positive vertical bars. ${ }^{a, b, c, d}$ Mean values with unlike superscript letters were significantly different (ANOVA with Bonferroni correction, $P<0.0025$ )

Table 3 Fatty acid proportions in plasma phospholipids according to high-level psychological distress (PD): James Bay Cree Indian adults aged 18 years and over

\begin{tabular}{|c|c|c|c|c|c|}
\hline \multirow[b]{3}{*}{ Fatty acids ( $\%$ of total) } & \multicolumn{4}{|c|}{ High-level PD } & \multirow[b]{3}{*}{$P$ value* } \\
\hline & \multicolumn{2}{|c|}{ Yes (n 154) } & \multicolumn{2}{|c|}{ No $(n 698)$} & \\
\hline & Mean & SD & Mean & SD & \\
\hline $\begin{array}{l}\text { Total } n-6 \text { PUFAt } \\
\text { LA }(18: 2 n-6) \\
\text { AA }(20: 4 n-6)\end{array}$ & $\begin{array}{r}31 \cdot 9 \\
19 \cdot 8 \\
8 \cdot 8\end{array}$ & $\begin{array}{l}2 \cdot 3 \\
2 \cdot 8 \\
1 \cdot 8\end{array}$ & $\begin{array}{r}30 \cdot 8 \\
18 \cdot 5 \\
9 \cdot 3\end{array}$ & $\begin{array}{l}2 \cdot 7 \\
3 \cdot 1 \\
1 \cdot 9\end{array}$ & $\begin{array}{c}<0.0001 \\
<0.0001 \\
0.004\end{array}$ \\
\hline $\begin{array}{l}\text { Total } n-3 \text { PUFA } \\
\alpha \text {-LNA }(18: 3 n-3) \\
\text { EPA }(20: 5 n-3) \\
\text { DPA } n-3(22: 5 n-3) \\
\text { DHA }(22: 6 n-3) \\
\text { Sum EPA + DHA } \\
\text { Sum EPA + DPA } n-3+\text { DHA }\end{array}$ & $\begin{array}{l}4 \cdot 2 \\
0 \cdot 21 \\
0 \cdot 60 \\
0 \cdot 68 \\
2 \cdot 5 \\
3 \cdot 1 \\
3 \cdot 8\end{array}$ & $\begin{array}{l}1 \cdot 3 \\
0 \cdot 10 \\
0 \cdot 46 \\
0 \cdot 21 \\
0 \cdot 9 \\
1 \cdot 2 \\
1 \cdot 3\end{array}$ & $\begin{array}{l}5 \cdot 2 \\
0 \cdot 21 \\
0 \cdot 93 \\
0 \cdot 74 \\
3 \cdot 1 \\
4 \cdot 1 \\
4 \cdot 8\end{array}$ & $\begin{array}{l}2 \cdot 2 \\
0 \cdot 10 \\
0 \cdot 86 \\
0 \cdot 24 \\
1 \cdot 2 \\
2 \cdot 0 \\
2 \cdot 1\end{array}$ & $\begin{array}{c}<0.0001 \\
0.68 \\
<0.0001 \\
0.008 \\
<0.0001 \\
<0.0001 \\
<0.0001\end{array}$ \\
\hline $\begin{array}{l}\text { Total } n-3 / \text { total } n-6 \\
\text { EPA/AA }\end{array}$ & $\begin{array}{l}0 \cdot 13 \\
0 \cdot 07\end{array}$ & $\begin{array}{l}0.05 \\
0.04\end{array}$ & $\begin{array}{l}0 \cdot 17 \\
0 \cdot 10\end{array}$ & $\begin{array}{l}0.09 \\
0.08\end{array}$ & $\begin{array}{l}<0.0001 \\
<0.0001\end{array}$ \\
\hline
\end{tabular}

LA, linoleic acid; AA, arachidonic acid; $\alpha$-LNA, $\alpha$-linolenic acid; DPA $n$-3, docosapentaenoic acid.

${ }^{*} P$ values were calculated for log-transformed fatty acids.

tSum of $n-6$ PUFA $(18: 2+18: 3+20: 2+20: 3+20: 4+22: 2+22: 4+22: 5)$.

$\ddagger$ Sum of $n-3$ PUFA $(18: 3+18: 4+20: 3+20: 4+20: 5+22: 5+22: 6)$.

proportions according to PDISQS-14 quintiles. Higher PDISQS-14 quintiles indicate higher PD scores, with the fifth quintile corresponding to the high-level PD category. A lower EPA + DHA proportion $(P$ for trend $<0 \cdot 0001)$ was observed with increasing quintile of PDISQS-14 scores, especially among those categorized as high-level PD. Comparison of EPA + DHA in plasma PL between extreme PDISQS-14 quintiles, the lowest distress score category (Q1) compared with the high-level PD category (Q5), indicated a difference of $1 \cdot 38 \%$ (95\% CI 0.84, $1.91 \%)$. PUFA proportions in plasma PL are enumerated in Table 3. Mean proportions of $n$-3 FA, except $\alpha$-LNA, were significantly lower in the PD group compared with the non-distressed group. Compared with non-distressed subjects, those with high-level PD had higher linoleic acid and lower AA proportions in their plasma PL.

Table 4 presents the OR for high-level PD according to the plasma PL tertiles of $n$ - 3 FA, with the lowest tertile group serving as the reference group. EPA was the only individual $n$-3 FA significantly associated with the risk of high-level PD in the multivariate model. Combinations of $\mathrm{EPA}+\mathrm{DHA}$ or $\mathrm{EPA}+$ docosapentaenoic acid 
Table 4 Odds ratios for high-level psychological distress (PD) according to tertile of $n-3$ fatty acids (FA) in plasma phospholipids: James Bay Cree Indian adults aged 18 years and over

\begin{tabular}{|c|c|c|c|c|c|c|c|c|}
\hline \multirow[b]{2}{*}{ FA tertile: median (range) } & \multicolumn{2}{|c|}{ High-level PD } & \multicolumn{2}{|c|}{ Crude } & \multicolumn{2}{|c|}{ Model $1^{*}$} & \multicolumn{2}{|c|}{ Model 2† } \\
\hline & No $(n)$ & Yes $(n)$ & OR & $95 \% \mathrm{Cl}$ & OR & $95 \% \mathrm{Cl}$ & OR & $95 \% \mathrm{Cl}$ \\
\hline \multicolumn{9}{|l|}{$\alpha$-LNA } \\
\hline T1: $0.14(0-0.17)$ & 236 & 47 & 1.00 & & 1.00 & & $1 \cdot 00$ & \\
\hline T2: $0.20(0.17-0.23)$ & 232 & 52 & $1 \cdot 13$ & $0.73,1.75$ & $1 \cdot 11$ & $0 \cdot 71,1 \cdot 74$ & $1 \cdot 16$ & $0 \cdot 73,1 \cdot 83$ \\
\hline T3: $0.28(0.23-0.97)$ & 230 & 55 & $1 \cdot 20$ & $0 \cdot 78,1 \cdot 85$ & $1 \cdot 16$ & $0 \cdot 74,1 \cdot 82$ & $1 \cdot 17$ & $0.73,1.86$ \\
\hline$P$ for trend & & & $0 \cdot 4097$ & & 0.5186 & & & 0.5113 \\
\hline \multicolumn{9}{|l|}{ EPA } \\
\hline T1: $0.36(0-0.45)$ & 221 & 62 & $1 \cdot 00$ & & $1 \cdot 00$ & & $1 \cdot 00$ & \\
\hline T2: $0.58(0.45-0.81)$ & 215 & 69 & $1 \cdot 13$ & $0.77,1.68$ & $1 \cdot 33$ & $0.89,2 \cdot 00$ & $1 \cdot 42$ & $0.93,2 \cdot 15$ \\
\hline T3: $1.32(0.81-7.35)$ & 262 & 23 & 0.29 & $0.17,0.49$ & 0.53 & $0.31,0.93$ & 0.56 & $0.32,0.99$ \\
\hline$P$ for trend & & & $<0.0001$ & & 0.0321 & & & 0.0535 \\
\hline \multicolumn{9}{|l|}{ DPAn-3 } \\
\hline T1: $0.54(0-0.62)$ & 217 & 66 & 1.00 & & 1.00 & & $1 \cdot 00$ & \\
\hline T2: $0.69(0.62-0.78)$ & 239 & 45 & 0.63 & $0.42,0.97$ & 0.79 & $0.51,1.22$ & $0 \cdot 77$ & $0.49,1 \cdot 20$ \\
\hline T3: $0.92(0.78-2.05)$ & 242 & 43 & 0.56 & $0.36,0.86$ & 1.07 & $0 \cdot 67,1 \cdot 71$ & $1 \cdot 13$ & $0 \cdot 70,1 \cdot 84$ \\
\hline$P$ for trend & & & 0.0079 & & $0 \cdot 8487$ & & & 0.6732 \\
\hline \multicolumn{9}{|l|}{$\mathrm{DHA}$} \\
\hline T1: $1.95(0.71-2.40)$ & 210 & 73 & 1.00 & & $1 \cdot 00$ & & $1 \cdot 00$ & \\
\hline T2: $2 \cdot 81(2 \cdot 40-3 \cdot 32)$ & 231 & 53 & 0.66 & $0.44,0.98$ & $0 \cdot 79$ & $0 \cdot 52,1 \cdot 20$ & $0 \cdot 84$ & $0.55,1 \cdot 28$ \\
\hline T3: $4.14(3.32-8 \cdot 20)$ & 257 & 28 & 0.29 & $0 \cdot 18,0.48$ & 0.57 & $0.34,0.97$ & 0.65 & $0 \cdot 38,1 \cdot 12$ \\
\hline$P$ for trend & & & $<0.0001$ & & 0.0356 & & & $0 \cdot 1146$ \\
\hline \multicolumn{9}{|l|}{ Sum EPA + DHA } \\
\hline T1: $2 \cdot 33(0 \cdot 88-2 \cdot 87)$ & 212 & 72 & 1.00 & & 1.00 & & $1 \cdot 00$ & \\
\hline T2: $3.42(2 \cdot 87-4 \cdot 10)$ & 226 & 57 & 0.72 & $0.49,1.07$ & 0.85 & $0 \cdot 57,1 \cdot 28$ & $0 \cdot 89$ & $0.59,1.36$ \\
\hline T3: $5.49(4 \cdot 10-13 \cdot 77)$ & 260 & 25 & $0 \cdot 26$ & $0 \cdot 16,0.42$ & 0.50 & $0.29,0.87$ & 0.56 & $0.32,0.98$ \\
\hline$P$ for trend & & & $<0.0001$ & & 0.0173 & & & 0.0495 \\
\hline \multicolumn{9}{|l|}{ Sum EPA + DPAn-3 + DHA } \\
\hline T1: $2.95(1.03-3.48)$ & 209 & 75 & $1 \cdot 00$ & & 1.00 & & $1 \cdot 00$ & \\
\hline T2: $4 \cdot 10(3 \cdot 48-4 \cdot 86)$ & 231 & 53 & 0.63 & $0.43,0.94$ & $0 \cdot 75$ & $0 \cdot 50,1 \cdot 13$ & $0 \cdot 79$ & $0.52,1 \cdot 20$ \\
\hline T3: $6 \cdot 37(4 \cdot 87-14 \cdot 67)$ & 258 & 26 & 0.25 & $0.15,0.41$ & 0.50 & $0.29,0.86$ & 0.55 & $0.32,0.97$ \\
\hline$P$ for trend & & & $<0.0001$ & & 0.0112 & & & 0.0368 \\
\hline \multicolumn{9}{|l|}{ Total $n-3$ PUFA } \\
\hline T1: $3 \cdot 28(1 \cdot 25-3 \cdot 84)$ & 196 & 73 & 1.00 & & $1 \cdot 00$ & & $1 \cdot 00$ & \\
\hline T2: $4.47(3 \cdot 85-5 \cdot 29)$ & 244 & 55 & $0 \cdot 61$ & $0.41,0.90$ & $0 \cdot 71$ & $0 \cdot 47,1 \cdot 07$ & $0 \cdot 75$ & $0 \cdot 49,1 \cdot 14$ \\
\hline T3: $6 \cdot 83(5 \cdot 30-15 \cdot 00)$ & 258 & 26 & 0.24 & $0 \cdot 15,0.40$ & 0.47 & $0.27,0.82$ & 0.52 & $0.30,0.92$ \\
\hline$P$ for trend & & & $<0.0001$ & & 0.0059 & & & 0.0207 \\
\hline
\end{tabular}

$\alpha$-LNA, $\alpha$-linolenic acid $(18: 3 n-3)$; EPA, $20: 5 n-3$; DPA $n-3$, docosapentaenoic acid $(22: 5 n-3) ;$ DHA, $22: 6 n-3 ;$ total $n-3$, sum of $n-3$ PUFA (18:3+ $18: 4+20: 3+20: 4+20: 5+22: 5+22: 6)$.

*Multivariate model 1 controlled for age and gender.

tMultivariate model 2 included the variables in multivariate model 1 and smoking status, recent stress events, education, total plasma cholesterol and chronic medical illness.

(DPA $n-3)+$ DHA or the sum of $n-3$ were all associated with the risk of high-level PD. Compared with the lowest $\mathrm{EPA}+\mathrm{DHA}$ tertile (median $=2 \cdot 3$ ), the model adjusted for age and sex indicated that the OR for high-level PD was 0.85 (95\% CI $0.57,1.28)$ for the second tertile (median $=3 \cdot 4)$ and $0.50(95 \%$ CI $0 \cdot 29,0 \cdot 87)$ for the third tertile (median $=5 \cdot 5)$. After controlling for confounders in the multivariate model, the OR for high-level PD was 0.89 (95\% CI $0.59,1.36)$ for the second tertile and 0.56 (95\% CI $0.32,0.98$ ) for the third tertile, compared with the lowest EPA + DHA tertile.

\section{Discussion}

In the present cross-sectional study, we noted significantly lower plasma content of EPA, DPA $n-3$ and DHA among subjects categorized as high-level PD compared with non-distressed subjects. After adjustment for confounders, EPA was the only individual $n$-3 FA significantly associated with the risk of high-level PD. Combinations of $\mathrm{EPA}+\mathrm{DHA}$ or EPA + DPA $n-3+\mathrm{DHA}$, or the sum of $n-3$, were also associated with the risk of high-level PD. Subjects in the third tertile of EPA + DHA in plasma PL had 1.8 times lower risk of having a high-level PD score compared with those in the lowest tertile.

Our results are in line with previous cross-sectional studies that reported an inverse relationship between fish consumption and depression ${ }^{(45-48)}$. In a cross-sectional analysis of $n-3$ plasma PL and PDISQS-14 among Nunavik Inuit, we recently noted that women in the second and third tertiles of EPA + DHA proportions in plasma PL had three times lower risk of a high-level PD score than women in the lowest tertile ${ }^{(49)}$. However, we did not 
observe this difference among men. In the Hordaland Health Study, users of cod-liver oil were less likely than non-users to have high levels of depressive symptoms on the Hospital Anxiety and Depression Scale, but not high levels of anxiety symptoms ${ }^{(50)}$. In 771 patients with newly diagnosed lung cancer, Suzuki et al. reported no association between EPA + DHA intake and the Depression Subscale of the Hospital Anxiety and Depression Scale (cut-off $\geq 5)^{(51)}$. However, they recorded a two times lower risk $(P<0 \cdot 05)$ in the fourth quartile of $\alpha$-LNA intake compared with the first quartile. In our analyses, we did not see a relationship between $\alpha$-LNA and PDISQS-14 scores. In a cross-sectional investigation of data from a nationally representative sample of $4644 \mathrm{New}$ Zealand adults, Silvers and Scott ${ }^{(52)}$ demonstrated that higher fish consumption was associated with higher selfreported mental health status.

Except for EPA, no individual $n$-3 FA was significantly associated with risk of high-level PD in the multivariate model. These results are in line with Three-City Study findings ${ }^{(48)}$. Cross-sectional analyses indicated that only plasma EPA, and not DHA, was inversely associated with the severity of depressive symptomatology among 1390 elderly French subjects. Some authors argue that studies of EPA alone or with a higher ratio of EPA to DHA are associated with better outcomes than trials of an enriched DHA supplement ${ }^{(33,53)}$. Our results might also be explained by the fact that EPA in blood appears to be less saturable than $\mathrm{DHA}^{(54,55)}$. Brown et al. ${ }^{(56)}$ suggested that DHA turnover in red blood cells (RBC) is slower than EPA. However, others have noted stronger correlations between fish intake and plasma DHA than $\mathrm{EPA}^{(57,58)}$. Nevertheless, it has been postulated that the combination of EPA and DHA may be a better independent variable to assess the health effects of $n$ - 3 LC PUFA consumption ${ }^{(59)}$.

To date, two cohort studies have prospectively analysed the association between $n$ - 3 intake and fish consumption and mental disorders ${ }^{(60,61)}$. The first, a longitudinal trial among 29133 Finnish men, failed to find an association between $n$-3 from fish and self-reported depressed mood or hospital treatment for major depression ${ }^{(60)}$. However, several limitations could explain these negative results $^{(15)}$. In the second, the SUN (Seguimiento University of Navarra) cohort study, only the fourth quintile of baseline $n$-3 LC PUFA intake was significantly associated with a lower risk of incident mental disorder (defined as self-reported physician diagnosis of depression, anxiety or stress or the use of antidepressant medications or tranquilizers). No linear trend was apparent between baseline $n$-3 LC PUFA intake and incident mental disorder after 2 years of follow-up. However, compared with the Structured Clinical Interview for DSM-IV, physician recognition of major depressive episode was poor (sensitivity $=40 \%)^{(62)}$. Moreover, the rates of untreated mental disorders are high in different countries ${ }^{(63)}$. Therefore, antidepressant medications and tranquilizers are also poor indicators of mental disorder. In addition, $n$-3 LC PUFA intakes were very high in this cohort. The first and fifth quintiles of median energy-adjusted $n-3$ LC PUFA intakes were respectively 0.39 and $1.89 \mathrm{~g} / \mathrm{d}$.

Our results must be interpreted in the context of the limitations and strengths of any cross-sectional study. As a consequence, we cannot ascertain any causal relationship and we cannot rule out the possibility that higher PD (especially if it was characterized by depression) influenced n-3 LC PUFA intakes from fish. A recent metaanalysis of double-blind, placebo-controlled studies has suggested that $n$-3 LC PUFA significantly improve symptoms in patients with clearly defined depression ${ }^{(64)}$. However, no major clinical investigation has been published, and the most significant trials tested $n$ - 3 LC PUFA supplementation as an adjunct to antidepressant therapy. Moreover, two recent meta-analyses on $n-3$ LC PUFA and depression noted significant heterogeneity and publication bias ${ }^{(64,65)}$. A weakness of our study is that the PDISQS-14 cannot be used to ascertain specific psychiatric disorders. However, the present analysis did not aim to assess the prevalence of specific psychiatric disorders but rather to identify if $n$-3 LC PUFA could be associated with the global index of PD. Even though severe PD cannot be directly expressed in terms of clinical psychiatric disorders, we can, however, postulate that the risk of psychopathology increases with the level of PD. It is possible that the outcomes noted in the PDISQS-14 were due to $n-3$ LC PUFA effects not only on depression but also on anxiety and hostility items. However, the literature on the relationship between $n$-3 LC PUFA and anxiety and hostility is less abundant than for depression. Indeed, some studies show the benefits of $n-3$ LC PUFA in anxiety disorders ${ }^{(66,67)}$ but others do not ${ }^{(50,68)}$. A role of $n$-3 LC PUFA has been suggested in disorders characterized by impulsivity ${ }^{(69)}$. However, in a recent randomized controlled trial among patients with recurrent self-harm, $\mathrm{EPA}+\mathrm{DHA}$ supplementation did not improve impulsivity, aggression or hostility ${ }^{(70)}$.

A single assessment of $n$ - 3 LC PUFA in blood reflects the ranking of $n-3$ LC PUFA intakes from fish ${ }^{(71)}$. Such biomarkers of FA intakes provide quantitative measurements independently of memory and/or knowledge of the subjects and are less likely to be due to social desirability bias than dietary self-reporting ${ }^{(72)}$. It is likely that our correlations might be influenced by the utilization of plasma PL rather than RBC analysis. Indeed, plasma PL FA determination reflects short-term intake better than RBC. According to the 18-month controlled study of Katan et al., half-maximal and maximal concentrations of EPA in RBC were reached after 28 and $180 \mathrm{~d}^{(73)}$. However, these stages were attained after $4 \cdot 8$ and $56 \mathrm{~d}$ for serum cholesteryl esters, indicating that RBC might reflect long-term intake better than plasma or serum. However, correlations between plasma PL and RBC DHA and EPA are strong ${ }^{(54,74)}$. Moreover, analysis of plasma EPA + DHA is 
not only a measure of traditional food consumption but also a yardstick for adherence to traditional behaviours such as fishing and hunting. It is, therefore, difficult to separate the biological effect of social behaviour adherence to Cree culture when EPA + DHA are measured. Furthermore, illicit drugs and alcohol consumption were not added in our multivariate model since these variables could be surrogate markers of PD and would lead to over-adjustment.

\section{Conclusion}

In the present retrospective cross-sectional study, we found that $n-3$ LC PUFA proportions in plasma PL, a marker of $n-3$ LC PUFA consumption from fish, were inversely associated with PD. These observations are consistent with other investigations indicating an effect of $n-3$ LC PUFA in mood disorders. However, the causal relationship between $n-3$ LC PUFA in plasma PL and mood in this population should be established prospectively.

\section{Acknowledgements}

The study was supported by Indian and Northern Affairs Canada. No authors have reported financial disclosures or conflicts of interest related to the present manuscript. The contributions of each author in this work are as follows: study concept and design - E.D., C.B., S.G. and M.L.; analysis of the data - M.L., E.D., S.G. and C.B.; interpretation of the data - M.L., E.D., C.B., S.G. and B.J.H.; drafting the manuscript - M.L. and E.D.; critical revision of the manuscript - M.L., E.D., C.B., S.G. and B.J.H. The authors acknowledge the close cooperation of Santé-Québec in providing access to health survey databases on the James Bay Cree. The authors also express their gratitude to the Cree Board of Health and Social Services of James Bay and to all participants in the Santé-Québec Health Survey.

\section{References}

1. Kirmayer LJ, Brass GM \& Tait CL (2000) The mental health of Aboriginal peoples: transformations of identity and community. Can J Psychiatry 45, 607-616.

2. McGrath-Hanna NK, Greene DM, Tavernier RJ \& Bult-Ito A (2003) Diet and mental health in the Arctic: is diet an important risk factor for mental health in circumpolar peoples? A review. Int J Circumpolar Health 62, 228-241.

3. Boothroyd LJ, Kirmayer LJ, Spreng S, Malus M \& Hodgins S (2000) Completed suicides among the Inuit of northern Quebec, 1982-1996: a case-control study. CMAJ 165, 749-755.

4. Waldram JB, Herring DA \& Young TK (2006) Aboriginal Health in Canada: Historical, Cultural, and Epidemiological Perspectives, 2nd ed. Toronto: University of Toronto Press.

5. Kirmayer LJ, Macdonald ME \& GM Brass (2000) The Mental Health of Indigenous Peoples. Report no. 10. Montreal: Culture \& Mental Health Research Unit, Institute of
Community \& Family Psychiatry, Sir Mortimer B. DavisJewish General Hospital.

6. Chandler MJ \& Lalonde C (1998) Cultural continuity as a hedge against suicide in Canada's First Nations. Transcult Psychiatry 35, 191-219.

7. Haggarty J, Cernovsky Z, Kermeen P \& Merskey H (2000) Psychiatric disorders in an Arctic community. Can J Psychiatry 45, 357-362.

8. Lavallée C, Robinson E \& Laverdure J (1991) Description of customers and services of mental health among the Cree people (North Quebec). Sante Cult 8, 265-284.

9. Santé-Québec, Daveluy C \& Bertrand L (editors) (1998) A Dietary Profile of the Cree: Report of the Santé Québec Health Survey of the James Bay Cree, 1991: Food and Nutrient Intake. Montréal: Ministère de la santé et des services sociaux, Government of Quebec.

10. Santé Québec, Daveluy C, Lavallée C, Clarkson M \& Robinson E (editors) (1994) A Health Profile of the Cree: Report of the Santé Québec Health Survey of the James Bay Cree 1991. Montréal: Ministère de la santé et des services sociaux, Government of Quebec.

11. Prince RH (1993) Psychiatry among the James Bay Cree: a focus on pathological grief reactions. Transcult Psychiatry Res Rev 30, 3-50.

12. Dewailly E, Blanchet C, Gingras S, Lemieux S \& Holub BJ (2002) Cardiovascular disease risk factors and $n$-3 fatty acid status in the adult population of James Bay Cree. Am J Clin Nutr 76, 85-92.

13. Hibbeln JR \& Salem N Jr (1995) Dietary polyunsaturated fatty acids and depression: when cholesterol does not satisfy. Am J Clin Nutr 62, 1-9.

14. Parker G, Gibson NA, Brotchie H, Heruc G, Rees AM \& Hadzi-Pavlovic D (2006) Omega-3 fatty acids and mood disorders. Am J Psychiatry 163, 969-978.

15. Sontrop J \& Campbell MK (2006) Omega-3 polyunsaturated fatty acids and depression: a review of the evidence and a methodological critique. Prev Med 42, 4-13.

16. Plourde M \& Cunnane S (2007) Extremely limited synthesis of long chain polyunsaturates in adults: implications for their dietary essentiality and use as supplements. Appl Physiol Nutr Metab 32, 619-634.

17. Kobayashi M, Sasaki S, Kawabata T, Hasegawa K \& Tsugane S (2003) Validity of a self-administered food frequency questionnaire used in the 5-year follow-up survey of the JPHC Study Cohort I to assess fatty acid intake: comparison with dietary records and serum phospholipid level. J Epidemiol 13, 1 Suppl., S64-S81.

18. Kuriki K, Nagaya T, Tokudome Y et al. (2003) Plasma concentrations of ( $n-3)$ highly unsaturated fatty acids are good biomarkers of relative dietary fatty acid intakes: a cross-sectional study. J Nutr 133, 3643-3650.

19. Hjartaker A, Lund E \& Bjerve KS (1997) Serum phospholipid fatty acid composition and habitual intake of marine foods registered by a semi-quantitative food frequency questionnaire. Eur J Clin Nutr 51, 736-742.

20. Yehuda S, Rabinovitz S \& Mostofsky DI (1999) Essential fatty acids are mediators of brain biochemistry and cognitive functions. J Neurosci Res 56, 565-570.

21. Martinez M (1992) Tissue levels of polyunsaturated fatty acids during early human development. J Pediatr 120, s129-s138.

22. McNamara RK \& Carlson SE (2006) Role of omega-3 fatty acids in brain development and function: potential implications for the pathogenesis and prevention of psychopathology. Prostaglandins Leukot Essent Fatty Acids 75, 329-349.

23. Delion S, Chalon S, Guilloteau D, Besnard JC \& Durand G (1996) $\alpha$-Linolenic acid dietary deficiency alters age-related changes of dopaminergic and serotoninergic neurotransmission in the rat frontal cortex. $J$ Neurochem 66, 1582-1591. 
24. Delion S, Chalon S, Guilloteau D, Lejeune B, Besnard JC \& Durand G (1997) Age-related changes in phospholipid fatty acid composition and monoaminergic neurotransmission in the hippocampus of rats fed a balanced or an $n-3$ polyunsaturated fatty acid-deficient diet. I Lipid Res 38, 680-689.

25. Delion S, Chalon S, Hérault J, Guilloteau D, Besnard J-C \& Durand G (1994) Chronic dietary $\alpha$-linolenic acid deficiency alters dopaminergic and serotoninergic neurotransmission in rats. J Nutr 124, 2466-2476.

26. de la Presa Owens S \& Innis SM (1999) Docosahexaenoic and arachidonic acid prevent a decrease in dopaminergic and serotoninergic neurotransmitters in frontal cortex caused by a linoleic and $\alpha$-linolenic acid deficient diet in formula-fed piglets. J Nutr 129, 2088-2093.

27. Kodas E, Galineau L, Bodard S, Vancassel S, Guilloteau D, Besnard JC \& Chalon S (2004) Serotoninergic neurotransmission is affected by $n-3$ polyunsaturated fatty acids in the rat. I Neurochem $\mathbf{8 9}, 695-702$

28. Hibbeln JR, Umhau JC, Linnoila M, George DT, Ragan PW, Shoaf SE, Vaughan MR, Rawlings R \& Salem N Jr (1998) A replication study of violent and nonviolent subjects: cerebrospinal fluid metabolites of serotonin and dopamine are predicted by plasma essential fatty acids. Biol Psychiatry 44, 243-249.

29. Hibbeln JR, Linnoila M, Umhau JC, Rawlings R, George DT \& Salem N Jr (1998) Essential fatty acids predict metabolites of serotonin and dopamine in cerebrospinal fluid among healthy control subjects, and early- and late-onset alcoholics. Biol Psychiatry 44, 235-242.

30. Serhan CN (2005) Novel omega-3 derived local mediators in anti-inflammation and resolution. Pharmacol Ther 105, $7-21$.

31. Farooqui AA, Horrocks LA \& Farooqui T (2007) Modulation of inflammation in brain: a matter of fat. J Neurochem 101, 577-599.

32. Haag M (2003) Essential fatty acids and the brain. Can J Psychiatry 48, 195-203.

33. Stahl LA, Begg DP, Weisinger RS \& Sinclair AJ (2008) The role of omega-3 fatty acids in mood disorders. Curr Opin Invest Drugs 9, 57-64.

34. Kirmayer LJ, Boothroyd LJ, Tanner A, Adelson N \& Robinson E (2000) Psychological distress among the Cree of James Bay. Transcult Psychiatry 37, 35-56.

35. Préville M, Boyer R \& Potvin L (1992) La détresse psychologique: détermination de la fiabilité et de la validité de la mesure utilisée dans l'enquête Santé Québec, enquête Santé Québec 1987. Les cahiers de recherche no. 7. Montréal: Ministère de la santé et des services sociaux, Government of Quebec.

36. Preville M, Potvin L \& Boyer R (1995) The structure of psychological distress. Psychol Rep 77, 275-293.

37. Ilfeld FW Jr (1978) Psychologic status of community residents along major demographic dimensions. Arch Gen Psychiatry 35, 716-724.

38. Ilfeld FW (1976) Further validation of a psychiatric symptom index in a normal population. Psychol Rep 39, $1215-1228$.

39. Martin F, Sabourin S \& Gendreau P (1989) Les dimensions de la detresse psychologique: analyse factorielle confirmatoire de type hierarchique. Int J Psychol 24, 571-584.

40. Boyer R, Preville M, Legare G \& Valois P (1993) Psychological distress in a noninstitutionalized population of Quebec: normative results of the Quebec health survey. Can J Psychiatry 38, 339-343.

41. Stark KD \& Holub BJ (2004) Differential eicosapentaenoic acid elevations and altered cardiovascular disease risk factor responses after supplementation with docosahexaenoic acid in postmenopausal women receiving and not receiving hormone replacement therapy. Am J Clin Nutr 79, 765-773.
42. Babyak MA (2004) What you see may not be what you get: a brief, nontechnical introduction to overfitting in regression-type models. Psychosom Med 66, 411-421.

43. Peduzzi P, Concato J, Kemper E, Holford TR \& Feinstein AR (1996) A simulation study of the number of events per variable in logistic regression analysis. J Clin Epidemiol 49, 1373-1379.

44. Steyerberg EW, Eijkemans MJ, Harrell FE Jr \& Habbema JD (2001) Prognostic modeling with logistic regression analysis: in search of a sensible strategy in small data sets. Med Decis Making 21, 45-56.

45. Timonen M, Horrobin D, Jokelainen J, Laitinen J, Herva A \& Rasanen P (2004) Fish consumption and depression: the Northern Finland 1966 birth cohort study. J Affect Disord 82, 447-452.

46. Tanskanen A, Hibbeln JR, Tuomilehto J, Uutela A, Haukkala A, Viinamaki H, Lehtonen J \& Vartiainen E (2001) Fish consumption and depressive symptoms in the general population in Finland. Psychiatr Serv 52, 529-531.

47. Kamphuis MH, Geerlings MI, Tijhuis MA, Kalmijn S, Grobbee DE \& Kromhout D (2006) Depression and cardiovascular mortality: a role for $n-3$ fatty acids? $A m J$ Clin Nutr 84, 1513-1517.

48. Feart C, Peuchant E, Letenneur L, Samieri C, Montagnier D, Fourrier-Reglat A \& Barberger-Gateau P (2008) Plasma eicosapentaenoic acid is inversely associated with severity of depressive symptomatology in the elderly: data from the Bordeaux sample of the Three-City Study. Am J Clin Nutr 87, 1156-1162.

49. Lucas M, Dewailly E, Blanchet B, Gingras S \& Holub BJ (2009) Plasma omega-3 and psychological distress among Nunavik Inuit (Canada). Psychiatry Res (In the Press).

50. Raeder MB, Steen VM, Vollset SE \& Bjelland I (2007) Associations between cod liver oil use and symptoms of depression: the Hordaland Health Study. J Affect Disord 101, 245-249.

51. Suzuki S, Akechi T, Kobayashi M, Taniguchi K, Goto K, Sasaki S, Tsugane S, Nishiwaki Y, Miyaoka H \& Uchitomi Y (2004) Daily omega-3 fatty acid intake and depression in Japanese patients with newly diagnosed lung cancer. Br J Cancer 90, 787-793.

52. Silvers KM \& Scott KM (2002) Fish consumption and selfreported physical and mental health status. Public Health Nutr 5, 427-431.

53. Kidd PM (2007) Omega-3 DHA and EPA for cognition, behavior, and mood: clinical findings and structural-functional synergies with cell membrane phospholipids. Altern Med Rev 12, 207-227.

54. Arterburn LM, Hall EB \& Oken H (2006) Distribution, interconversion, and dose response of $n-3$ fatty acids in humans. Am J Clin Nutr 83, 6 Suppl., 1467S-1476S.

55. Brown AJ, Pang E \& Roberts DCK (1991) Erythrocyte eicosapentaenoic acid versus docosahexaenoic acid as a marker for fish and fish oil consumption. Prostaglandins Leukot Essent Fatty Acids 44, 103-106.

56. Brown AJ, Pang E \& Roberts DC (1991) Persistent changes in the fatty acid composition of erythrocyte membranes after moderate intake of $n$-3 polyunsaturated fatty acids: study design implications. Am J Clin Nutr $\mathbf{5 4}$, $668-673$

57. Mina K, Fritschi L \& Knuiman M (2007) A valid semiquantitative food frequency questionnaire to measure fish consumption. Eur J Clin Nutr 61, 1023-1031.

58. Woods RK, Stoney RM, Ireland PD, Bailey MJ, Raven JM, Thien FC, Walters EH \& Abramson MJ (2002) A valid food frequency questionnaire for measuring dietary fish intake. Asia Pac J Clin Nutr 11, 56-61.

59. Harris WS \& Von Schacky C (2004) The Omega-3 Index: a new risk factor for death from coronary heart disease? Prev Med 39, 212-220. 
60. Hakkarainen R, Partonen T, Haukka J, Virtamo J, Albanes D \& Lonnqvist J (2004) Is low dietary intake of omega-3 fatty acids associated with depression? Am J Psychiatry 161, 567-569.

61. Sanchez-Villegas A, Henriquez P, Figueiras A, Ortuno F, Lahortiga F \& Martinez-Gonzalez MA (2007) Long chain omega-3 fatty acids intake, fish consumption and mental disorders in the SUN cohort study. Eur J Nutr 46, 337-346.

62. Lowe B, Spitzer RL, Grafe K, Kroenke K, Quenter A, Zipfel S, Buchholz C, Witte S \& Herzog W (2004) Comparative validity of three screening questionnaires for DSM-IV depressive disorders and physicians' diagnoses. I Affect Disord 78, 131-140.

63. Bijl RV, de Graaf R, Hiripi E et al. (2003) The prevalence of treated and untreated mental disorders in five countries. Health Aff (Millwood) 22, 122-133.

64. Lin PY \& Su KP (2007) A meta-analytic review of doubleblind, placebo-controlled trials of antidepressant efficacy of omega-3 fatty acids. J Clin Psychiatry 68, 1056-1061.

65. Appleton KM, Hayward RC, Gunnell D, Peters TJ, Rogers PJ, Kessler D \& Ness AR (2006) Effects of $n$-3 long-chain polyunsaturated fatty acids on depressed mood: systematic review of published trials. Am J Clin Nutr 84, 1308-1316.

66. Green P, Hermesh H, Monselise A, Marom S, Presburger G \& Weizman A (2006) Red cell membrane omega-3 fatty acids are decreased in nondepressed patients with social anxiety disorder. Eur Neuropsychopharmacol 16, 107-113.

67. Buydens-Branchey L \& Branchey M (2006) n-3 Polyunsaturated fatty acids decrease anxiety feelings in a population of substance abusers. J Clin Psychopharmacol 26, 661-665.

68. Fux M, Benjamin J \& Nemets B (2004) A placebo-controlled cross-over trial of adjunctive EPA in OCD. J Psychiatr Res 38, 323-325.

69. Hallahan B \& Garland MR (2004) Essential fatty acids and their role in the treatment of impulsivity disorders. Prostaglandins Leukot Essent Fatty Acids 71, 211-216.

70. Hallahan B, Hibbeln JR, Davis JM \& Garland MR (2007) Omega-3 fatty acid supplementation in patients with recurrent self-harm. Single-centre double-blind randomised controlled trial. Br J Psychiatry 190, 118-122.

71. Kobayashi M, Sasaki S, Kawabata T, Hasegawa K, Akabane M \& Tsugane S (2001) Single measurement of serum phospholipid fatty acid as a biomarker of specific fatty acid intake in middle-aged Japanese men. Eur J Clin Nutr $\mathbf{5 5}$, 643-650.

72. Hebert JR, Ma Y, Clemow L, Ockene IS, Saperia G, Stanek EJ 3rd, Merriam PA \& Ockene JK (1997) Gender differences in social desirability and social approval bias in dietary selfreport. Am J Epidemiol 146, 1046-1055.

73. Katan MB, Deslypere JP, van Birgelen APJM, Penders M \& Zegwaard M (1997) Kinetics of the incorporation of dietary fatty acids into serum cholesteryl esters, erythrocyte membranes, and adipose tissue: an 18-month controlled study. J Lipid Res 38, 2012-2022.

74. Sun Q, Ma J, Campos H, Hankinson SE \& Hu FB (2007) Comparison between plasma and erythrocyte fatty acid content as biomarkers of fatty acid intake in US women. Am J Clin Nutr 86, 74-81. 